\title{
Reaction Path of the Oxidative Coupling of Methane over a Lithium-doped Magnesium Oxide Catalyst
}

\section{Factors affecting the Rate of Total Oxidation of Ethane and Ethylene}

\author{
I A. ROOS S.J KORF, R.H.J. VEEHOF, J.G. VAN OMMEN and J.R.H. ROSS* \\ Eaculty of Chemical Technology, University of Twente, P.O. Box 217, 7500 AE Enschede (The \\ Netherlands)
}

(Received G January 1989, revised manuscript received 29 March 1989)

\section{ABSTRACT}

Experiments using gas mixtures of $\mathrm{O}_{2}, \mathrm{C}_{2} \mathrm{H}_{6}$ or $\mathrm{C}_{2} \mathrm{H}_{4}$ and $\mathrm{CH}_{4}$ or He have been carried out with a $\mathrm{Li} / \mathrm{MgO}$ catalyst using a well-mixed reaction system which show that the total oxidation prodweis $\mathrm{CO}$ and $\mathrm{CO}_{2}$, are formed predominantly from ethylene, formed in the oxidative coupling of methane It is therefore concluded that the network of reactions taking place during oxidative coupling of methane over a Li-doped $\mathrm{MgO}$ catalyst can be simplified to a serial reaction scheme: $\mathrm{CH}_{4} \rightarrow \mathrm{C}_{2} \mathrm{H}_{6} \rightarrow \mathrm{C}_{2} \mathrm{H}_{4} \rightarrow \mathrm{CO}_{x}$. Additional experiments have shown that the rates of gas-phase oxidation reaction of $\mathrm{C}_{2} \mathrm{H}_{6}$ and $\mathrm{C}_{2} \mathrm{H}_{4}$ are lowered by the presence of excess $\mathrm{CH}_{4}$ or by alkali metal carbonates

\section{INTRODUCTION}

In the oxidative coupling of methane to give higher hydrocarbons, it is important to suppress kinetically the rates of formation of carbon oxides relative to those of the desired products as the formation of carbon oxides is thermodynamically more favourable. A general reaction scheme for the reactions leading to the formation of $\mathrm{C}_{2} \mathrm{H}_{6}, \mathrm{C}_{2} \mathrm{H}_{4}$ and total oxidation products, $\mathrm{CO}_{x}$ (i.e. $\mathrm{CO}$ and $\mathrm{CO}_{2}$ ) is shown in Fig. 1 [1-3]; this is a network in which $\mathrm{CO}_{x}$ may be

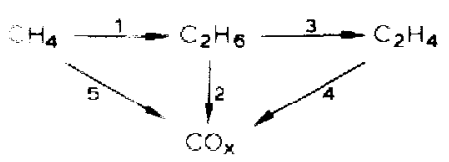

Fig. 1. General reaction scheme for the oxidative coupling of $\mathrm{CH}_{4}$ to $\mathrm{C}_{2} \mathrm{H}_{6}$ and $\mathrm{C}_{2} \mathrm{H}_{4}$. 
formed both directly from the reactant methane (i.e. parallel to the desired reaction) as from the $\mathrm{C}_{2}$ products (i.e. a consecutive path). It is important to gain a clear idea of the relative importance of each of these steps as such an understanding might lead to the development of more selective catalyst. A number of proposals have been made concerning the reaction network for varions catalyst systems. For example, Ito et al. [1] and Otsuka et al. [2] have proposed a parallel mechanism for the case of $\mathrm{Li} / \mathrm{MgO}$ and $\mathrm{Sm}_{2} \mathrm{O}_{3}$ catalysts respectively. Basing their arguments on measurements of the rates of total catalytic oxidation of ethane or ethylene compared to that of methane at temperatures of $610-620^{\circ} \mathrm{C}$, both sets of authors concluded that $\mathrm{CO}$ and $\mathrm{CO}_{2}$ are formed directly from methane (reaction 5 of Fig. 1 ).

Labinger and Ott [4] and Sofranko and co-workers [5,6], who studied supported $\mathrm{Mn}_{2} \mathrm{O}_{3}$ catalysts using cyclic modes of operation, assume however that further oxidation of the higher hydrocarbons formed takes place, especially at higher conversions. This conclusion was based on measurements showing the effect of residence time on product selectivity: extrapolation back to zero residence time resulted in $100 \%$ selectivity for ethane. Results from our laboratory have also shown that total oxidation reactions of ethane and ethylene play an important role in the formation of total oxidation products [7]. We found that the addition (in low concentrations) of ethane or ethylene to a methane/ oxygen gas mixture used as the feed to a $\mathrm{Li} / \mathrm{MgO}$ or $\mathrm{Ca} / \mathrm{Sm}_{2} \mathrm{O}_{3}$ catalyst resulted in a decrease of the methane conversion by competition between the $\mathrm{C}_{2}$ molecules and methane for the available oxygen; the oxygen conversion was total in all the experiments. We argued that this indicates that ethane and ethy lene are more reactive with oxygen (to give $\mathrm{CO}_{x}$ and water) than is methane These results tended to favour a sequential mechanism. The assumption that the $\mathrm{C}_{2}$ products are intermediates in the route to total oxidation products explained the previous observation that better $\mathrm{C}_{2}$ selectivities were obtained in a plug flow reactor than in a reactor where some back-mixing occurred [8].

This article reports the results of experiments aimed at determining the relative importance of the individual reactions in the overall reaction scheme of Fig. 1. It will be shown that reactions 3 and 4 are catalysed by the $\mathrm{Li} / \mathrm{MgO}$ catalvst, and that these reactions also take place in the gas phase at higher reaction temperatures. The rate of these gas-phase oxidation reactions is lowered by the presence of excess methane or alkali metal carbonates.

\section{EXPFRIMENT AI.}

\section{Reaction systems}

The majority of the experiments have been performed in a recycle system, described in detail elsewhere [9]. The reaction system behaves as a gradientless reactor with respect to gas-phase concentrations, this being achieved by 
external recirculation of the product gas using a membrane pump. Various different gases may be fed to the reaction system: $\mathrm{O}_{2}, \mathrm{CH}_{4}, \mathrm{C}_{2} \mathrm{H}_{4}, \mathrm{CO}_{2}, \mathrm{CO}$ and $\mathrm{He}$ By adjusting the concentration of any one or more of these gases in the feed, its concentration in the catalyst bed can be kept at a desired value.

The experiments aimed at the determination of the effect of alkali carbonates on the rate of oxidation of $\mathrm{C}_{2} \mathrm{H}_{6}$ and $\mathrm{C}_{2} \mathrm{H}_{4}$ (see Results and Discussion) were performed in a tubular (fused alumina) single-pass flow reactor with a heated length of $40 \mathrm{~cm}$. A small bed of $500 \mathrm{mg} \mathrm{Na} \mathrm{CO}_{3}$ or $\mathrm{K}_{2} \mathrm{CO}_{3}$ (bed length $3-4)$ was placed in the middle of the reactor. A gas mixture containing $2.8 \mathrm{kPa}$ of $\mathrm{C}_{2} \mathrm{H}_{4}$ or $\mathrm{C}_{2} \mathrm{H}_{4}$ or $\mathrm{C}_{2} \mathrm{H}_{6}$ and $3.6 \mathrm{kPa}$ of $\mathrm{O}_{2}$ (balance $\mathrm{He}$, total pressure $=101$ $\mathrm{kPa}$ ) was fed to the reactor (flow-rate $3.3 \mathrm{~cm}^{3} \mathrm{~s}^{-1}$ (STP)).

\section{Catalyst}

The same $\mathrm{Li} / \mathrm{MgO}$ catalyst was used as was used in the experiments described in previous publications $[9,10]$.

\section{RESULTS AND DISCUSSION}

\section{Experiments at $720^{\circ} \mathrm{C}$, determination of the reaction path}

As outlined in the introduction it is important to understand the source of the total oxidation products. A number of experiments in which the effect of a variation of the partial pressure of $\mathrm{CH}_{4}, \mathrm{C}_{2} \mathrm{H}_{6}$ and $\mathrm{C}_{2} \mathrm{H}_{4}$ (at a constant partial pressure of oxygen) on the rate of formation of total oxidation products $\left(\mathrm{CO}_{x}\right)$ was determined have therefore been performed with a $\mathrm{Li} / \mathrm{MgO}$ catalyst using the recycle system. The results are shown in Table 1 . The reaction temperature was chosen to be $720^{\circ} \mathrm{C}$ as previous experiments [7] have shown that the rates of gas-phase oxidation reactions of $\mathrm{CH}_{4}, \mathrm{C}_{2} \mathrm{H}_{6}$ and $\mathrm{C}_{2} \mathrm{H}_{4}$ are negligible under

\section{TABLE 1}

Rate of formation of $\mathrm{CO}$ and $\mathrm{CO}_{2}$ indation experiments, in which the reactor was filled with $500 \mathrm{mg}$ of $\mathrm{L} / \mathrm{MgO}$ catalyst, $T=720^{\circ} \mathrm{C}$

\begin{tabular}{|c|c|c|c|c|c|}
\hline & \multicolumn{5}{|c|}{ Hydrocarbons in reactor feed } \\
\hline & $1: \mathrm{C}_{2} \mathrm{H}_{4}$ & $2: \mathrm{CH}_{4} / \mathrm{C}_{2} \mathrm{H}_{4}$ & $3: \mathrm{C}_{2} \mathrm{H}_{6}$ & $4: \mathrm{CH}_{4} / \mathrm{C}_{2} \mathrm{H}_{6}$ & $5: \mathrm{CH}_{4}$ \\
\hline$P_{0} / \mathrm{kPa}$ & 5.4 & 5.7 & 5.8 & 5.5 & 5.6 \\
\hline$P_{\mathrm{CH}_{4}} / \mathrm{kPa}$ & 0.3 & 103.3 & 0.5 & 100.9 & 113.5 \\
\hline$P_{\mathrm{H}_{\mathrm{f}}} / \mathrm{kPa}$ & 0.0 & 1.4 & 7.6 & 7.5 & 2.1 \\
\hline$P_{\mathrm{H} / \mathrm{kPa}}$ & 6.3 & 6.3 & 6.1 & 6.5 & 1.9 \\
\hline$R_{\mathrm{O}_{\mathrm{x}}} / 10^{-7} \mathrm{~mol} \cdot \mathrm{s}^{-1}$ & 3.9 & 4.0 & 4.0 & 4.5 & 2.1 \\
\hline
\end{tabular}


these conditions. The initiation of the reactions of the hydrocarbons is thus strictly catalytic at this temperature; we cannot however exclude the possibility that the hydrocarbon radicals formed by the catalyst may react further in the gas phase.

The five columns in Table 1 represent five different experiments. The first four rows give the partial pressures of $\mathrm{O}_{2}, \mathrm{CH}_{4}, \mathrm{C}_{2} \mathrm{H}_{6}$ and $\mathrm{C}_{2} \mathrm{H}_{4}$ as measured at the exit of the reactor; as the reactor is practically gradientless (see above), these concentrations can be taken to be the concentrations throughout the reactor. The last row gives the rate of $\mathrm{CO}_{x}$-formation for all the experiments. In the first experiment, the gas feed consisted of a mixture of $\mathrm{O}_{2}, \mathrm{C}_{2} \mathrm{H}_{4}$ and $\mathrm{He}$; in the second of $\mathrm{O}_{2}, \mathrm{CH}_{4}$ and $\mathrm{C}_{2} \mathrm{H}_{4}$; in the third of $\mathrm{O}_{2}, \mathrm{C}_{2} \mathrm{H}_{6}$ and $\mathrm{He}$; in the fourth of $\mathrm{O}_{2}, \mathrm{C}_{2} \mathrm{H}_{6}$ and $\mathrm{CH}_{4}$; and in the fifth of $\mathrm{O}_{2}, \mathrm{CH}_{4}$ and $\mathrm{He}$. In all cases, the concentrations of $\mathrm{O}_{2}$ in the reactor feed was adjusted to maintain the same partial pressure in the catalyst bed; further, almost the same partial pressures of $\mathrm{C}_{2} \mathrm{H}_{4}$ and $\mathrm{C}_{2} \mathrm{H}_{6}$ were used in the first and second and the third and fourth experiments, respectively. Making use of the results of Table 1, the following observations can be made regarding the reaction network shown in Fig. 1:

(i) The relative importance of reaction 5 , i.e. the formation of $\mathrm{CO}_{x}$ directly from methane, can be derived by a comparison of columns 1 to 4 of Table 1 . It can be seen that a variation by a factor of 340 of the partial pressure of methane in the (ideally mixed) reactor (columns 1 and 2) does not affect the rate of $\mathrm{CO}_{x}$ formation. We therefore conclude that the contribution of reaction 5 is negligible in the case of the $\mathrm{Li} / \mathrm{MgO}$ catalyst under these conditions.

(ii) The importance of reaction 2, i.e. the formation of $\mathrm{CO}_{x}$ from ethane, can also be derived from a comparison of columns 1 to 4 of Table 1 . A change of the partial pressure of ethane from zero (column 1) to $7.6 \mathrm{kPa}$ (column 3) hardly affects the rate of $\mathrm{CO}_{x}$ formation. We therefore also conclude that there is a negligible contribution from reaction 2 to the overall reaction scheme. The rate of $\mathrm{CO}_{x}$ formation thus appears only to be affected (at least in this series of experiments carried out at constant temperature and oxygen partial pressure) by the partial pressure of ethylene; compare the results of column 5 with those of the other columns of the table. In the experiment of column 5 , the partial pressure of ethylene is lower than in the other experiments and this is the only experiment with a significantly lower rate of $\mathrm{CO}_{x}$ formation. We therefore propose that the overall reaction scheme for the reactions taking place in the oxidative coupling of methane in the presence of a $\mathrm{Li} / \mathrm{MgO}$ catalyst at a reaction temperature of $720^{\circ} \mathrm{C}$ can be simplified to the sequential reaction scheme shown in Fig. 2.

It has been shown earlier [9] that the oxidative coupling reaction of meth-

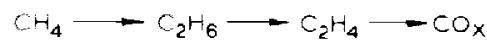

Fig. 2. Reaction scheme for the oxidative coupling of methane over a $\mathrm{Li} / \mathrm{MgO}$ catalyst $\left(T=720^{\circ} \mathrm{C}\right)$. 
ane over a $\mathrm{Li} / \mathrm{MgO}$ catalyst may be described by an Langmuir-Hinshelwood type mechanism in which competitive adsorption of $\mathrm{O}_{2}$ (and possibly $\mathrm{CH}_{4}$ ) on the active sites of the catalyst plays an important role. We can now also conclude that the oxidation reactions of $\mathrm{C}_{2} \mathrm{H}_{6}$ and $\mathrm{C}_{2} \mathrm{H}_{4}$ at $720^{\circ} \mathrm{C}$ are also accelerated by the $\mathrm{Li} / \mathrm{MgO}$ catalyst, as the gas-phase reactions of these molecules are negligible at this temperature. It is not yet clear whether or not these reactions take place on the same sites at which the activation of methane occurs or on separate (total oxidation) sites. If molecules other than methane (e.g. $\mathrm{C}_{2} \mathrm{H}_{6}$ and $\mathrm{C}_{2} \mathrm{H}_{4}$ ) react on the sites which cause the activation of methane, the adsorption of these molecules (i.e. in competition with methane) should also be incorporated in the detailed kinetic expression for the reaction.

\section{Reactions at $800^{\circ} \mathrm{C}$}

It has been shown above that at a reaction temperature of $720^{\circ} \mathrm{C}$, the total oxidation products are formed solely from $\mathrm{C}_{2} \mathrm{H}_{4}$. At this temperature, the rates of gas-phase oxidation reactions of $\mathrm{CH}_{4}, \mathrm{C}_{2} \mathrm{H}_{6}$ and $\mathrm{C}_{2} \mathrm{H}_{4}$ are negligibly low under our conditions. However, at a reaction temperature of $800^{\circ} \mathrm{C}$, gas-phase oxidation reactions are likely to be of more importance [7] and to compete with the catalytic reactions. It is therefore interesting to attempt to obtain the reaction network at this temperature also. It will be shown below, however, that an effect of methane on the rates of the total oxidation reactions of $\mathrm{C}_{2} \mathrm{H}_{6}$ and $\mathrm{C}_{2} \mathrm{H}_{4}$ in the gas phase [11] makes it difficult to reach such definite conclusions as were reached for reactions at $720^{\circ} \mathrm{C}$.

\section{Experiments with a reactor packed with quartz}

The effect of the presence of excess methane on the rate of oxidation of ethylene in the absence of a catalyst is shown in Table 2; these measurements

\section{TABLE 2}

Rates of production of $\mathrm{CO}$ and $\mathrm{CO}_{2}$ in sxidation experiments in which the reactor was filled with quartz, $T=800^{\circ} \mathrm{C}$

\begin{tabular}{llc}
\hline & \multicolumn{2}{l}{ Hydrocarbons in reactor feed } \\
\cline { 2 - 3 } & $1: \mathrm{C}_{2} \mathrm{H}_{4}$ & $2 . \mathrm{CH}_{4} / \mathrm{C}_{2} \mathrm{H}_{4}$ \\
\hline$P_{\mathrm{O}_{2}} / \mathrm{kPa}$ & 3.0 & 2.9 \\
$P_{\mathrm{CH}_{4}} / \mathrm{kPa}$ & 1.4 & 117.8 \\
$P_{\mathrm{O}_{2} \mathrm{H}_{6}} / \mathrm{kPa}$ & 0.1 & 0.3 \\
$P_{\mathrm{O}_{2} \mathrm{H}_{4}} / \mathrm{kPa}$ & 3.3 & 3.3 \\
$R_{\mathrm{CO}_{x}} / 10^{-7} \mathrm{~mol}^{-1}$ & 6.2 & 0.8 \\
\hline
\end{tabular}


were performed in the recycle system at a temperature of $800^{\circ} \mathrm{C}$ with a bed of quartz particles replacing the catalyst bed. The experiment shown in column 1 clearly indicates that the rate of total oxidation of ethylene in the gas phase is relatively high if the methane concentration is low. (It is here assumed that quartz is catalytically inactive [7]; see also below.) The gas-phase oxidation of ethylene thus takes place readily at $800^{\circ} \mathrm{C}$. However, if the concentration of methane is increased, the concentration of oxygen and ethylene being kept the same, the rate of $\mathrm{CO}_{x}$ formation is much diminished: see column 2. Analogous results to those shown in Table 2 were achieved with ethane in place of ethylene.

Experiments with a catalyst

Table 3 shows similar experiments to those given in Table 2, the reaction temperature again being $800^{\circ} \mathrm{C}$; however, in this case the reactor contained the $\mathrm{Li} / \mathrm{MgO}$ catalyst $\left(500 \mathrm{mg}\right.$ ). Comparison of the rates of $\mathrm{CO}_{x}$ formation in the two experiments of Table 3 shows that the inhibiting effect of excess methane (i.e. the difference in the rates of $\mathrm{CO}_{x}$ formation with and without excess $\mathrm{CH}_{4}$ ) on the rate of total oxidation of ethylene is still present, but that it is less pronounced. Analogous results to those shown in Table 3 were obtained when ethane was used in place of ethylene.

The fact that the inhibiting effect of methane on the rate of ethylene oxidation is smaller in the presence of the $\mathrm{Li} / \mathrm{MgO}$ catalyst than in the presence of quartz (only gas-phase reactions) can be explained by suggesting that the presence of excess methane lowers only the rates of the gas-phase oxidation reactions of the $\mathrm{C}_{2}$ products, while the rates of the catalytic reactions of these compounds are not significantly influenced by methane. At a temperature of $800^{\circ} \mathrm{C}$ with a $\mathrm{Li} / \mathrm{MgO}$ catalyst present, both gas-phase and catalytic reactions probably take place. Accordingly, the presence of excess methane will have a smaller effect on the rate of ethylene oxidation in the experiments with the $\mathrm{Li}$ /

\section{TABLE 3}

Rate of formation of $\mathrm{CO}$ and $\mathrm{CO}_{2}$ in oxidation experiments, in which the reactor was filled with $500 \mathrm{mg}$ of $\mathrm{Li} / \mathrm{MgO}$ catalyst, $T=800^{\circ} \mathrm{C}$

\begin{tabular}{llc}
\hline & \multicolumn{2}{l}{ Hydrocarbons in reactor feed } \\
\cline { 2 - 3 } & $1: \mathrm{C}_{2} \mathrm{H}_{4}$ & $2: \mathrm{CH}_{4} / \mathrm{C}_{2} \mathrm{H}_{4}$ \\
\hline$P_{\mathrm{O}_{2}} / \mathrm{kPa}$ & 2.2 & 2.2 \\
$P_{\mathrm{CH}} / \mathrm{kPa}$ & 0.4 & 119.1 \\
$P_{\mathrm{C}_{2} \mathrm{H}_{6}} / \mathrm{kPa}$ & 0.1 & 1.6 \\
$P_{\mathrm{C}_{2} \mathrm{H}_{4}} / \mathrm{kPa}$ & 3.7 & 3.7 \\
$R_{\mathrm{CO}} / 10^{-7} \mathrm{~mol} \cdot \mathrm{s}^{-1}$ & 6.4 & 4.7 \\
\hline
\end{tabular}


$\mathrm{MgO}$ catalyst present than in the case of a reactor filled with quartz particles: with the catalyst, the reactions will take place in the gas phase only to a limited degree. At a reaction temperature of $720^{\circ} \mathrm{C}$, when the rates of gas-phase oxidation reactions of $\mathrm{CH}_{4}, \mathrm{C}_{2} \mathrm{H}_{6}$ and $\mathrm{C}_{2} \mathrm{H}_{4}$ are negligible (see above), it would thus be expected that the presence of excess methane has now no effect on the rates of the oxidation reactions of $\mathrm{C}_{2} \mathrm{H}_{6}$ and $\mathrm{C}_{2} \mathrm{H}_{4}$. Table 1 (see above) shows that this is indeed the case; compare columns 1 and 2 and columns 3 and 4 .

The inhibiting effect of methane on the rate of gas-phase oxidation of ethane and ethylene can be explained by a reduction of the number of active chain carriers (or replacement of active chain carriers by less active ones) in the propagation steps of the chain reactions taking place. In these reactions, radicals such as $\mathrm{H}, \mathrm{O}, \mathrm{OH}$, as well as hydrocarbon radicals play an important role [12]. Removal of these radicals (by the $\mathrm{CH}_{4}$ or a product of the $\mathrm{CH}_{4}$ ) will thus lead to a lower rate of oxidation of the hydrocarbon. This explanation is analogous to the explanation which has been advanced for the observed inhibition of the $\mathrm{H}_{2} / \mathrm{O}_{2}$ reaction by various hydrocarbons, including methane [13]: in this case, the hydrocarbon $\mathrm{RH}$ reacts with a $\mathrm{H}$ radical to form an $\mathrm{R}$ radical and $\mathrm{H}_{2}$.

$\mathrm{RH}+\mathrm{H} \rightarrow \mathrm{R}+\mathrm{H}_{2}$

If ethane or higher hydrocarbons are added to a $\mathrm{H}_{2} / \mathrm{O}_{2}$ mixture, reaction (1) leads to chain termination as the alkyl radicals $\left(\mathrm{C}_{2} \mathrm{H}_{5}, \mathrm{C}_{3} \mathrm{H}_{7}\right.$, etc. $)$ have low reactivity [13]. In the case of methane however, an active $\mathrm{CH}_{3}$ radical is formed with is capable of continuing the reaction chain by reaction (2):

$\mathrm{CH}_{3}+\mathrm{O}_{2} \rightarrow \mathrm{HCHO}+\mathrm{OH}$

Although the reactive $\mathrm{OH}$ radical is formed, the all-over effect is inhibitory as formaldehyde is also formed in reaction (2) [13]; formaldehyde has been shown to be extremely effective as an inhibitor, bringing about the removal of chain carriers [14]. We suggest that this explanation may also be applied to the case of the lowering of the rates of gas-phase reaction of $\mathrm{C}_{2} \mathrm{H}_{6}$ and $\mathrm{C}_{2} \mathrm{H}_{4}$ caused by the presence of excess $\mathrm{CH}_{4}$. In the experiments reported in Table 2, the formaldehyde concentration is probably much higher in the case of excess $\mathrm{CH}_{4}$ (column 2) than in the case of excess He (column 1); this may thus explain the inhibiting effect of excess $\mathrm{CH}_{4}$ on the oxidation of $\mathrm{C}_{2} \mathrm{H}_{6}$ and $\mathrm{C}_{2} \mathrm{H}_{4}$.

The surpressing effect of methane on the rate of $\mathrm{C}_{2}$ oxidation at a reaction temperature of $800^{\circ} \mathrm{C}$ makes it impossible to drawn conclusions regarding the importance of formation of $\mathrm{CO}_{x}$ direct from methane (reaction 5 of Fig. 1) compared to that from the $\mathrm{C}_{2}$ products (reactions 2 and 4 ); this is because the partial pressure of methane cannot be varied without having an effect on the rates of reactions (2) or (4). (In the experiments of Table 1, the methane concentration was varied over a wide range to determine the contribution of reaction 5 to the total reaction network). Although we have shown earlier [7] 
that the oxidation reactions of the $\mathrm{C}_{2}$ products at $800^{\circ} \mathrm{C}$ are very important, we cannot exclude on the basis of the results shown above that some formation on $\mathrm{CO}_{x}$ direct from $\mathrm{CH}_{4}$ may occur at temperatures above $720^{\circ} \mathrm{C}$; however, we believe that it will be a relatively small contribution.

Effect of alkali carbonates on the rates of total oxidation reactions of ethane and ethylene

It has been reported in the literature that the oxidation of hydrocarbons in a flame may be retarded by injecting e.g. finely powdered $\mathrm{Na}_{2} \mathrm{CO}_{3}$ into the flame $[12,15]$. Many other compounds may also be active as flame retardants, e.g. $\mathrm{K}_{2} \mathrm{SO}_{4}, \mathrm{NaCl}, \mathrm{CuCl}, \mathrm{NaHCO}_{3}$ or $\mathrm{KHCO}_{3}[15,16]$. This flame retarding effect of the alkali carbonates has been explained in two ways: (i) there is a thermal inhibition, in which the decomposition of $\mathrm{Na}_{2} \mathrm{CO}_{3}$ absorbs heat from the flame, thus lowering reaction rates [6]; (ii) there is a chemical inhibition in which alkali hydroxides are believed to be formed from the carbonate, these reacting with a hydrogen radical (a very reactive chain carrier) to form the alkali metal atom and water $[12,15,17]$. The alkali hydroxide is reformed by the reaction of the alkali metal with an (also very reactive) $\mathrm{OH}$ radical. The rate of the oxidation reaction is thus lowered by the removal of active chain carriers.

The effect of $\mathrm{Na}_{2} \mathrm{CO}_{3}$ and $\mathrm{K}_{2} \mathrm{CO}_{3}$ on the rate of oxidation of ethane and ethylene in the gas phase was investigated in a single-pass flow reactor with a small bed of $500 \mathrm{mg}$ of $\mathrm{Na}_{2} \mathrm{CO}_{3}$ or $\mathrm{K}_{2} \mathrm{CO}_{3}$ (see Experimental) and the results were compared with those of reaction without added alkaline carbonate. Fig. 3 shows the oxygen conversion of the reaction of ethylene with oxygen as function of the reaction temperature in four situations in which the reactor was filled with a bed of $\mathrm{Na}_{2} \mathrm{CO}_{3}, \mathrm{~K}_{2} \mathrm{CO}_{3}$ or quartz or in which a clean empty reactor

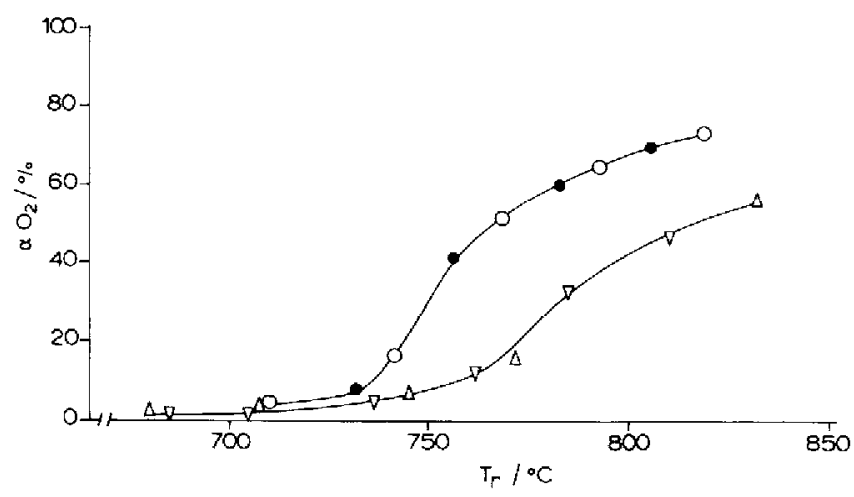

Fig. 3. The oxidation of $\mathrm{C}_{2} \mathrm{H}_{4}$ in a single-pass tubular reactor, with an without alkali carbonates present in the reactor: oxygen conversion as a function of reactor temperature; $(O)$ empty, quartz, $(\nabla) \mathrm{Na}_{2} \mathrm{CO}_{3},(\Delta) \mathrm{K}_{2} \mathrm{CO}_{3}$. 
was used. The experiment with the bed of quartz particles was performed so that exactly the same residence time was obtained as in the experiments with a bed of alkali carbonate. This experiment resulted in exactly the same oxygen conversion (as a function of the temperature) as in the experiment with the empty reactor. As the bed fills only a small part of the reactor tube and there has been a small change in the empty volume (but a large change in surface area due to the addition of quartz particles which have a large surface area compared to the reactor wall), we can conclude (see earlier) that quartz is catalytically inactive. Fig. 3 clearly shows that the presence of $\mathrm{Na}_{2} \mathrm{CO}_{3}$ or $\mathrm{K}_{2} \mathrm{CO}_{3}$ lowers the total oxidation rate of ethylene, even though only a small part of the volume of the reactor is filled with the alkali carbonate. Analogous results were obtained for the oxidation of ethane.

The first explanation of the flame retarding effect of alkali carbonates, i.e. that there is a removal of heat from the flame (see above), is not applicable to this experiment as the temperature in the reactor is kept constant by the oven and the bed of alkali carbonate only takes up a small part of the reactor. The second, chemical explanation is therefore favoured: the alkali carbonates are volatilized and reduce the number of chain carriers of the oxidation reaction, thereby lowering the reaction rate. We thus conclude that the rates of the gasphase oxidation reactions of ethane and ehtylene are lowered by the presence of $\mathrm{Na}_{2} \mathrm{CO}_{3}$ or $\mathrm{K}_{2} \mathrm{CO}_{3}$. Li $\mathrm{CO}_{3}$ probably has the same effect but could not be used for these experiments because it melts under the conditions used. However, it is not only in the gas phase that addition of alkali promoters lowers the oxidation rate of $\mathrm{C}_{2}$ products. It is known from the literature [1] that the addition of alkali promoters to $\mathrm{MgO}$ lowers its total oxidation activity, favouring the formation of $\mathrm{C}_{2}$ products; this reaction is thought to proceeding the gas phase near the surface of the catalyst [1]. It has been shown above that in the case of a $\mathrm{Li} / \mathrm{MgO}$ catalyst, the formation of $\mathrm{CO}_{x}$ proceeds through $\mathrm{C}_{2} \mathrm{H}_{4}$. The beneficial effect of alkali addition on the selectivity of an $\mathrm{MgO}$ catalyst may thus partly be explained by a decrease by the alkali promoter of the rate of oxidation of $\mathrm{C}_{2} \mathrm{H}_{4}$ at the catalyst surface as well as in the gas phase, in a way analogous to that outlined above.

\section{CONCLUSIONS}

(i) The reactions taking place during the oxidative coupling of methane in the presence of a $\mathrm{Li} / \mathrm{MgO}$ catalyst at a reaction temperature of $720^{\circ} \mathrm{C}$ follow a sequential reaction scheme, as shown in Fig. 2.

(ii) The gas-phase total oxidation of ethane and ethylene is retarded by the presence of excess methane and of alkali carbonates. 


\section{ACKNOWLEDGEMENTS}

S.J.K. thanks the Dutch Foundation for Scientific Research for financial support. We also thank J.A. Vreeman for technical assistance and the NonNuclear Energy programme of the European Community for partial support of the work (Contract No. EN3C-039-NL (GDF)). Finally, we should also like to thank the Salt and Basic Chemicals Division of Akzo for a financial contribution.

\section{REFERENCES}

1 T. Ito, J.-X. Wang, C.-H. Lin and J.H. Lunsford, J. Amer. Chem. Soc., 107 (1985) 5062.

2 K. Otsuka, K. Jinno and A. Morikawa, J. Catal., 100 (1986) 353.

3 W. Hinsen, W. Bytyn and M. Baerns, Proc. 8th. Int. Congr. Catal., Berlin, 1984 Verlag Chemie, Weinheim, 1984, Vol. III, p. 581.

4 J.A. Labinger and K.C. Ott, J. Phys. Chem., 91 (1987) 2682.

5 J.A. Sofranko, J.J. Leonard and C.A. Jones, J. Catal., 103 (1987) 302.

6 C.A. Jones, J.J. Leonard and J.A. Sofranko, J. Catal., 103 (1987) 311.

7 J.A. Roos, S.J. Korf, R.H.J. Veehof, J.G. van Ommen and J.R.H. Ross, Catal. Today, 4 (1989) 441.

8 J.A. Roos, S.J. Korf, A.G. Bakker, N.A. de Rruijn, J.G. van Ommen and J.R.H. Ross, in C.M. Bibby, C.D. Chang, R.F. Howe and S. Yurchak (Editors), Methane Conversion, Elsevier, Amsterdam, 1988, p. 427.

9 J.A. Roos, S.J. Korf, R.H.J. Veehof, J.G. van Ommen and J.R.H. Ross, Appl. Catal., 52 (1989) 131.

10 S.J. Korf, J.A. Roos, N.A. de Bruijn, J.G. van Ommen and J.R.H. Ross, Catal. Today, 2 (1988) 535.

11 J.H. Edwards, private communication.

12 H. Wise and W.A. Rosser, 9th Symp. (Int.) on Combustion, Cornell University, Ithica, NY, 1962, p. 733 .

13 R.R. Baldwin, N.S. Corney, P. Doran, L. Mayor and R.W. Walker, 9th Symp. (Int.) on Combustion, Cornell University, Ithica, NY, 1962, p. 184.

14 B. Lewis and G. von Elbe, Combustion, Flames and Explosions of Gases, Academic Press, New York and London, 1961, pp. 96, 126.

15 W.A. Rosser, Jr, S.H. Inami and H. Wise, Combust. Flame, 7 (2) (1963) 107.

16 T. Mitani and T. Niioka, 19th Symp. (Int.) on Combustion, Haifa, 1982 p. 869.

17 M. Vanpee and P.P. Shirodkar, 17th Int. Symp. on Combustion, Leeds, 1978, p. 787. 